\title{
As Transformações do Federalismo (*)
}

\author{
Candido Motta Filho \\ (Catedrática de Direito Constitucional)
}

Há mais de um século que o Éstado federal provoca discussões. E ontem, como hoje, é ainda uma iluminada esperança dos homens livres. À semelhança das pirâmides de Mênfis, que mudam de fisionomia conforme a posição assumida pelo observador, tem êle várias e perturbadoras aparências. Olhado de dentro para fora, é união; olhado de fora para dentro, é unidade. Para uns, confunde-se com a descentralização; para outros, é uma composição. CARLS Schmirt chega a vê-lo "como um Estado federal sem fundamentos federais". E Frangors Perroux acentua a ambiguidade que atinge em cheio a propria idéia do federalismo. Antes se recusava a amoldar-se às teorias, tanto assim que Rexnaldo Porchat, um dos primeiros professores da geração republicana desta Faculdade, em dissertação de 1897, se refere à "lamentável confusão a respeito do Estado federal". Hoje, a mesma insubordinação continua, não vacilando o ilustre jurista francês LETREIT DE LACHARRière, no seu estudo sôbre o ideal federativo na Rússia, em afirmar que "os exemplos históricos do federalismo jamais coincidem com os tipos clássicos, abstratos e ideológicos".

Essa imprecisão de fronteiras. fecunda e teimosa, provocou tamanha literatura que poderiamos, como o bibliotecário do Jacinto, do conto de Eça de Queiroz, colecionar,

(*) Aula de encerramento do curso juridico de 1951. 
para poupar espaço, os autores "que irreconciliàvelmente se contradizem".

Não há, como se vê, qualquer privilégio brasileiro, muito menos motivo para se dizer com PJNTES de MIRANDA. que, "sociològicamente, o caso brasileiro constituiu peça teratológica". Onde houve federação, houve processo federativo, acompanhado de suas antimônias, dificuldades e incertezas. Entre nós, convém que se assinale, - êsse se impõs com interessantes singularidades provindas da nossa Índole histórica $\mathrm{e}$ da nossa conformação geográfica.

Disse Euclides da Cunha que somos o único povo construído por uma teoria política. Mas, se é verdade que adotamos a experiência cultural do Velho Mundo, sempre tivemos que colocá-la a serviço de nossas circunstâncias. E é o que vem acontecendo com o nosso federalismo. Quando, na Constituinte monárquica, aparece a proposta de uma Federação de Ferreira França, apenas se renova uma aspiração de forma mais precisa. O VISCONDE do URUGUAI, ao fazer as suas recordações históricas sôbre o Ato adicional, diz que nos anos de 1830 e 1831 progrediram no Império "idéias de Federação". E confessa, contudo, que não encontra nesse tempo "idéias fixas e claras sôbre um sistema federativo para o Brasil". Por isso, o Manifesto Republicano, de 1870, vem dizer que "antes ainda da idéia democrática, encarregou-se a natureza de estabelecer o princípio federativo". Por êsse tempo, Tavares Bastos publicava "A Província" para debater, como assunto imperioso, federação e a descentralização.

Vitorioso, com a República, o ideal federativo, para êle se voltam os que pretendem solocionar os problemas políticos e os problemas da administração. Esse ideal, com Tavares Bastos em 1870, com Nabuco em 1888, com Rur BARBosa, em 1889, tem maior alcance do que a própria República.

RuI, que, desde os tempos da monarquia, muito mais se preocupava com a organização do Estado do que com a 
organização pròpriamente de govêrno, no famoso discurso que pronunciou em 16 de Novembro de 1890, avivou, com extraordinária lucidez, o significado da Federação na organização das liberdades. As franquias constitucionais, num sistema de Estados autônomos dentro da União soberana, decorreriam da capacidade que teria o povo de compreendê-las. Rui, que era o apóstolo do federalismo, que o proclamava com a monarquia ou sem ela, tomou, entretanto, logo de início, a defesa das prerrogativas da União, que estavam ameaçadas pelo que chama de "apetite desordenado e doentio de federalismo". Corajosamente declarava, em meio do fanatismo dos conversos: - "A f'ederação teria demorado o advento do regime republicano, por pouco tempo; mas teria poupado à República as dificuldades de organização".

A leitura dos anais da Constituinte de 1890 leva, de imediato, a perceber, em tôda a sua extensão, o novo compromisso que ia assumir a revolução vitoriosa, transformando em Estado federal, um Estado unitário: províncias pobres e províncias ricas, províncias grandes e pequenas, zonas civilizadas e outras tràgicamente alheias aos benefícios da civilização. E, acentuando êsse desencontro, em plenário constituinte, aparecia o exagêro ideológico, ameaçando os fundamentos da vida nacional. "Vêde, dizia Rur, êste abismo entre a solidez prática daqueles saxônicos, educados no govêrno de si mesmos, que fundavam, a poder de bom-senso e liberdade temperada, a maior das federações conheciđas na história e o descomedimento de nossa avidez. Ontem de federação não tínhamos nada. Hoje, não há federação que nos baste".

Na prática, a República federativa não podia caminhar fàcilmente. A realidade político-social proporcionou rupturas com as doutrinas e com as aspirações da liberdade e de organização. E do drama dessas rupturas que devastavam a fé republicana, participava RuI, que ora sentia o terror da prepotência da caudilhagem local, vitimando as 
populações inermes do interior brasileiro ora a prepotência do poder federal, fazendo estremecer, entre pânicos e ruínas, a cidade de Salvador, com o fogo dos canhões do forte de São Marcelo!

Por muito tempo, assim, o federalismo significou um jogo político, uma forma de conquista de poder. Muito embora se lutasse por uma discriminação de rendas de forma realmente a assegurar a autonomia dos Fstados membros; muito embora Júlio dE CASTILHo prevenisse que o conteúdo da Federação estava na discriminação de rendas, o descontentamento era visivel. A União se sentia lesada, conforme demonstrava o senador LEOpoldo ButurõEs, e alguns Estados se mantinham com dificuldade. F daí a justa observação de Veiga Filho: - "a crença, habilmente explorada, de ter havido completa desigualdade na partilha, sustentando uns que a federação ficou desprovida de recursos para ocorrer às suas despesas e outros, que tal fato sa deu com os Estados e Municípios - provocou abusos e invasões de competências".

Depois de vinte e cinco anos de República podia então o grande Alberto Tôrres dizer: - "Somos de um federalismo nominal, intransigente e o nosso autonomismo partidário não é senão a máquina que elabora a mais anemiada centralização social e econômica". Para êle, o nosso país ainda estava à espera de uma organização nacional. De um lado, havia o excessivo estadualismo; de outro, o excessivo centralismo. E daí a sua conclusão paradoxal: "O nosso federalismo é justamente o oposto da federação".

A guerra mundial, que terminou em 1918, descobrindo até raízes a crise da civilização, abalou os fundamentos de nossa vida pública, tornando ainda mais agudos os nossos problemas. Daí por deante, a União, ameaçada pelo desequilíbrio mundial no plano internacional e ameaçada pela incomunicabilidade dos Estados no plano interno, tomou a ofensiva. Propugnou-se, logo depois dela, uma reforma orgânica, por um revisionismo substancial, baseado em 
dados sociais e históricos. E é, nesse período, que aparece o pensamento de Oliveira Viana, em atitude de protesto contra o nosso idealismo marginalista. "Na verdade, diz êle, temos sacrificado por simples marginalismo ideológico muito de nossa organização política e da nossa tranquilidade pública ao mito da Federação e da Descentralização".

OliveIra Viana refletia assim um novo panorama que despontava no país. Já em 1924 é publicado urn interessante inquérito, que recolhes a pensamento dos escritores da geração nascida com a República. Ela procurava ser ouvida num momento semelhante a aquêle em que pontificaram homens da altitude de Evaristo da Veiga, de Bernardo Vasconcelos e de Diogo FeiJó. Pensava-se numa obra de reconstrução capaz de impedir o naufrágio das instituições livres. A Federação aparecia nesse passo, sem os suportes necessários para defender as liberdades democráticas. $E^{\prime}$ justamente nesse inquérito que Oliverra Viana erguia a bandeira contra o poder das fórmulas escritas, contra o preconceito das reorganizações políticas só por meios políticos. E' nesse inquérito que Pontes DE MIRANDA pontificava: - "Não queremos eliminar o Estado, mas regenerá-lo". Alceu dE Amoroso Lima nem sequer via a Federação. "A República, dizia êle, hoje, em trinta e cinco anos de realização, é o resultante de duas fôrças contraditórias: - o cesarismo e o caudilhismo".

As transformações culturais, a substituição do racionalismo metafísico pelo naturalismo experimental, a safra surpreendente de novos dados politicos, sociais e económicos, a participação do trabalhador no jôgo das ambições coletivas, o comunismo e o fascismo fizeram com que os povos procurassem nova técnica para a defesa de suas liberdades e de seus sistemas de vida. E nesse quadro se verifica um movimento de retôrno para o centro nos paíse: organizados em bases federativas. 
Os Estados Unidos, que já no govêrno de Teodoro RooSEVELT, tinham dado os primeiros passos para o centro, caminharam para êle, em marcha acelerada, depois de 1918.

Com efeito, o federalismo contratualista de CaLrroun, que dera resultados desastrosos na guerra civil, substituída pela doutrina do equilíbrio permanente de CHASE, não deixou sinais. Rui Barbosa diz que a tendência para a centralização nos Estados Unidos pode ser vista já em 1850. Porém, em nossos dias, é o govêrno de Franklin Roosevelt que dá o sinal para que a ofensiva pela centralização prossiga com um caráter vigoroso e em larga escala, em nome dos interêsses da justiça social.

Logo que assumiu o poder, a situação americana era realmente delicada. Em 1931, o desemprêgo chegara a proporções alarmantes. A existência de quinze milhões de desempregados propiciava as greves, as desordens, chegando, no comêço de 1937, a verificar-se a ocupação das principais oficinas da "General Motors". A revista "Life" não relutou, em nome dos interêsses conservadores, em comparar essa ocupação ao histerismo das danças de São Guido, na Idade Média!

Para acudir a situação, rompe o govêrno federal as linhas tradicionais do federalismo para sustentar uma nova política. Em pouco tempo, através de comissões e subcomissões, ela vence a resistência da Suprema Côrte, em cujos recintos vozes diferentes começam a ser ouvidas, como as de Holmes e Brandeis, que tinham visíveis popularidade nos meis trabalhistas. O professor RaUl Padover podia dizer então que "desde o momento em que se instalava na Casa Branca, o Presidente se torna o mais poderoso homem do mundo. Só pode ser comprado, em poder e em influência, ao Chefe da União Soviética. Antes não era assim. LASKr observou bem as dificuldades do Presidente da República, diante das desconfianças e exigências do Congresso. Marriman Smith vai ao ponto de comparálo a uma fortaleza cercada permanentemente. 
O Executivo era, de início, quase que um poder desarmado, movimentando-se discretamente com oitocentos funcionários. Hoje, é êle um poder atuante, que se movimenta com um exército de dois milhões de funcionários! Estudando objetivamente essa tranformação, Herberi' EMmerich, em seu ensaio sôbre a organização federal ame-. ricana conclui que o poder federal, que passa por um contínuo processo de transformação, abandonou a concepção de um federalismo "estático" para a de um federalismo "dinâmico". Em 1935, quando ainda se efetivavam as medidas do "New Deal", MCLAUGHLIN, na sua "História Constitucional dos Estados Unidos", dizia: - "O fato mais evidente da história constitucional americana, nos últimos trinta ou quarenta anos, é a expansão do govêrno nacional. Apesar do federalismo existir como estrutura teórica da Uniăo, êle não tem mais fundamento na consciência pública". $\mathrm{E}$, procurando explicar o alargamento do poder nacional, aponta, entre outras razões, a desigualdade dos Estadosmembros e as questões trabalhistas e económicas. Com isso, diz êle, surgiu a necessidade do auxílio federal a vários Estados, auxílio êsse que se completou com a adoção d'a moderna administração por planejamentos, que chega a abranger, por iniciativa federal, regiões de sete Estadosmembros, como aconteceu com a famosa corporação de di. reito público - "Tennessee Valley Authòrity", um dos pilares do "New Deal". Por sua vez, a Comissão de Recursos Nacionais (National Ressources Committee"), divide o país em várias regiões para levar a efeito o planejamento económico.

Tudo isso se faz sem maiores perturbações constitucjonais, atravez de emendas que estabelecem o aumento do poder fiscal da União e também pelo reconhecimento de poderes implicitos, que derivam daqueles expressamente delegados. Assim, baseando-se em preceito que autoriza 0 Congresso a regular o comércio entre os diversos Estados, a União neles penetra, atuando por sôbre o tráfego, energia 
elétrica, bôlsa, comércio à custa do trabalho infantil, comunicações, telégrafo, telefone, estradas e rádio.

Não houve aliás uma federação que não sentisse a influência das transformações sociais e que não seguisse a rumo já previsto por JellNeK, quand'o afirmou que, se o Estado federal é soberano, não tem limite a extensão de. sua competência em relação aos Estados-membros. O que aconteceu nos Estados Unidos, aconteceu, em escalas diversas, em outros países. Na República Argentina, Linares QuintanA, no seu livro "Teoria y pratica del Estado federal", revela que o federalismo argentino, voltando-se contra as trincheiras constitucionais, está em crise pela ameaça que existe de completo aniquilamento das províncias. E assinala que, nas conferências dos Ministros da Fazenua, realizadas em Buenos Aires, só se tratou de criar um clima favorável à centralização. A Federação Suíça, onde não há, como nota André Siegrried, unidade de raça, de língua, dé cultura, de religião, o poder central vem ganhando tôdas as partidas. Quando, em 1948, se comemorou o centenário da Constituição, o exame feito das estradas percorridas levou a essa conclusão. O mesmo fenômeno se observa no México, onde não só o govêrno da União procura estar presente em todo país, como ainda reclama uma melhor divisão geográfica da República para facilitar um desenvolvimento harmônico de todos os grupos sociais do Estado.

A federação brasileira não pôde se furtar à lógica universal. Teòricamente foi envolvida em muitos planos, inclusive de uma nova divisão territorial. Em 1925, LEVy Carneiro, em sua conferência sôbre "Federalismo e Judicialismo", apontava o crescimento, entre nós, da competência federal, com os impostos diretos, especialmente os de sêlo, o de consumo e o de renda. A superitendência e a fiscalização do ensino, a regulamentação do exercício das profissões liberais; os serviços do Ministério da Agricultura e da Saúde Pública o serviço militar; a distribuição de melhoramentos locais; as subvenções aos Estados; empreen- 
dimentos industriais e comerciais com o auxílio do Banco do Brasil e do "Lloyd brasileiro", a burocrecia federal cadx. vez maior, têm dado ao govêrno federal fôrça crescente, domínio esmagador sôbre os Estados. Os impostos interestaduais foram condenados, dizia êle. As polícias estaduais transformaram-se, por lei federal, em fôrças de segunda linha do exército nacional. E acrescenta por fim, avivando as tintas: - “ $O$ govêrno federal proíbe, e proíbe até por simples portaria de ministro, a importação ou exportação dêste ou daquele artigo".

A reforma constitucional de 1926, destinada, no dizer de Herculano de Freitas, a precisar as linhas demarcatórias das competência, não quis sustar o avanço da tendència centralizadora, porque a nau lo Estado já navegava com maus ventos.

Logo que nos reunimos em Assembléia Constituinte, em 1934, estávamos dispostos a injetar em nosso federalismo as lições dos teóricos da democracia social de Weimar. E a Federação foi objeto de interessantes debates. Não só o sistema de discriminação de rendas foi revisto, como ainda outros dados necessários à organização federativa foram postos na pauta das discussões. Um dêles é o senado, porque a Comissão do Itamarati, encarregada do anteprojeto constitucional, discutiu a sua supressão. Pois o senado não é uma das colunas mais sólidas da Federação? Pois o senado, proporcionando a representação igual dos Estados-membros, não é órgão que se destina, nas lições provectas de Hamilton e DE MEDison, a reconhecer a autonomia dos Estados-membros? O senador dizia Ru, é a personificação eletiva de um Estado. E o senado "é uma espécie de Dieta Federal onde cada Estado mantém, digamos assim, a sua embaixada permanente. O Sr. Joño MaNGABEIRA, consideroura porém institulição retrogada e sem significado atual na federação. E, apesar de não ter sofrido condenação, no diploma básico de 34 , nêle surgiu com um significado equítvoco, uma vez que, pelo artigo 89. 
"ao Senado incumbe promover a coordenação dos poderes federais entre si e manter a continuidade administrativa, velar pela Constituição, colaborar na feitura das leis e praticar os demais atos de sua competência".

Restaurado agora, dentro dos princípios proclamadios em 1891, o senado, contudo, mostrou-se profundamente federativo. Muito embora, pelo artigo 60 da Constituição de 46, seja composto de representantes dos Estados e do Distrito Federal, eleitos segundo o princípio majoritário, êle se alimenta por outras raízes. Em virtude da consagração, entre nós, do Estado de partidos; em consequência, por isso mesmo, da aplicação do sistema proporcional, os senadores, na verdade, - não representam os Estadosmembros, mas são representantes da opinião dos partidos de caráter nacional. E, para tanto, o artigo 47, do Código Eleitoral estabelece que "sòmente podem concorrer às eleições candidatos registrados por partidos ou aliança de partidos"

Não escapiamos, assim, ao destino universal do federaTismo, com a nossa situação agravada pela origem unitária de nossa formação. No Brasil, com efeito, o poder federal inicia o seu avanço, com os primeiros governos republicanos. E nunca tivemos um Presidente que se considerasse, tà maneira americana, uma fortaleza constantemente cercada. O Presidente venceu, com facilidade, tôdas as tentativas de cêrco. Em abril de 1892, no discurso que pronunciou no Supremo, Rui Barbosa, mostrando que o país estava com o número de seus senadores reduzidos, por decretos do Exxecutivo, concluía: - "A União federal está ferida no coração. A União federal já não existe. Procurem-lhe os farrapos nos decretos ditatórios do govêrno".

E quando a ordem civil se solidifica, Prudente de Morais era levado a dissolver as brigadas partidárias de Francisco Glicério, porque, com elas, o poder federal não existiria. José Maria dos Santos descreve, no seu livro sôbre a politica geral do Brasil, a vitória de Prudente de Morais, como 
presidente da República, sôbre o Partido Republicano Federal. A eleição do Presidente da Càmara dos Deputados e a designação de um novo lider foram ordenadas pelo Catete, a despeito da confiança que Francisco Glicerio depositava em seus correligionários. "O grande chefe, diz José Maria dos Santos, iludia-se lamentàvelmente, com as possibilidades do parlamento e a significação dos Estados, no regime federativo presidencial".

Êsse poder político do Presidente, que o tornava também "um fazedor de reis" como o Dugue de Malborough, cresceu e floresceu como uma planta nativa. Em 1899, Epitácio Pessoa, como Ministro da Justiça, já denunciava "a exorbitante faculdade dada ao Executivo no tocante 'd função de regularmentar as leis". O govêrno federal começou a ser considerado, desde êsse tempo, como uma hipertrofia do Executivo e também se falava, desde êsse tempo, no poder pessoal do Presidente, como um poder intruso, conforme qualificava, o Manifesto de 70 o poder pessoal do Imperador.

Pelo Presidente da República, a nova centralisação foi levando de vencida a resistência dos Estados. Senhor de um prestigio paternal, que vicejou no campo de nossa pobreza política à custa da insuficiência dos nossos partidos, das dificuldades financeiras de muitos Estados e, principalmente, pela rivalidade operante entre êles, o Presidente se tornou a razão de ser da politica nacional. O farol da autonomia não bastava para conter a competição política, afouta e desordenada, para a conquista do poder central. E a federação, como um corpo informe, era o teatro de violências, acentuadas pelos abusos das intervenções federais e das ideclarações de estado de sítio.

Quando o senador Pinheiro Machado, que dirigia ì sombra do Catete a política nacional, foi assassinado, o Partido Republicano Conservador ficou sem chefia. E o senador URBano dos SANTos declarava melancòlicamente: - - 
"Não há mais partido. O partido é o Presidente da República, em tôrno do qual vai girar a politica".

Esse federalismo político, deformado pelas condições. da época e pelo paternalismo presidencial, era no entanto desprovido, administrativamente, de meios e de programas para realizar uma obra de penetração nos Estados. Nas vésperas de 1930 , a revolução, que se preparava, era a prova de que não podíamos chegar ainda a uma conclusão e sim a um conflito. E essa revolução, dirigida oficialmente por três Estados da Federação foi, de um certo modo, logo no seu primeiro impulso, uma derrota do poder federal, pela derrota do Presidente da República. Diante desse desequilíbrio, que poderia levar o país à desintegração, surgia um outro perigo, que foi a reação oposta pela centralização.

Quando a República volta à sobriedade constituciona: e se refazem as antigas bases democráticas e federativas, já as regras do jôgo eram outras e não se podia ocultar uma vitória da União, através de um programa de recuperação de fôrças perdidas e que estabelecia medidas em nome da salvação nacional e a necessidade de se incorporar o Estado federal na lógica das novas conquistas sociais. A Constituição de 46 reforçou assim a vitória do poder da União em matéria judiciária, eleitoral, militar, municipal, orçamentária, de discriminação de rendas, de funcionalismo público. Proclamando uma ordem económica, organizada conforme os princípios da justiça social, estabelecendo que a União poderá, mediante lei especial, intervir no domínio económico e monopolizar determinada indústria ou atividade, que a lei facilitará a fixação do homem no campo; estabelecendo planos de colonização ede aproveitamento das terras públicas; of erecendo as bases para a legislação do trabalho e da previdência social; dispondo que a entrada, distribuição e fixação do imigrante ficarão sujeitas às exigências do interêsse nacional, cabendo a um órgão federal orientar êsses serviços; cuidando do 
plano de defesa contra os efeitos da sêca no nordeste e do plano da valorização económica da Amazônia - a Constituição proclama o poder da União, como um poder atuante e sem contrastes.

Éstamos agora diante de uma máquina federal poderosa e extensa, que se faz sentir por tôda parte. Foi construída aos poucos, na cumplicidade das prepotências políticas e depois, ao chegar aos nossos dias, se distendeu como uma rêde espêssa e fechada que cobre todo o território nacional. Quando vigoravam os princípios da Constituição de 91, percebem-se os primeiros e vagos ensaios de economia dirigida, que se desfazem por inoperantes Tentam-na, na primeira década do século atual, os governos de Campos Sales e Rodrigues Alves. O café, considerado o nosso principal produto, é, a principio, a preocupação dos Estados produtores. Em 1896, êsses Estados se reúnem em Petrópolis, apenas com a simpatia do govêrno federal. Êste, porém, já se manifesta, em 1906, quando é autorizado, por lei, a entrar em acôrdo com os Estados cafeeiros para regular o comércio cafeeiro e promover a sua valorização. Em 1922, quando o país estremece sob as agitações revolucionárias, o presidente EPITÁcio PessoA, em mensagem dirigida ao Congresso, afirmando que a situação da lavoura era das mais alarmantes, esclarece que, para a defesa do café, o govêrno resolveu intervir no mercado. Em 1924, quando a intervenção do Estado no plano económico mais se acentuava, o presidente ArTur Bernardes proclama a vitória do interêsse federal sôbre a divergência dos Estados produtores. Em 1933, a politica do café está dominada pelo poder federal e funciona através do Departamento Nacional do Café e da Carteira de Crédito Agrícola do Banco do Brasil. E até a luta pela melhoria do produto se faz por intermédio do Serviço Técnico do Café, do Ministério da Agricultura. Nesse ano, o Govêrno Federal faz surgirem numerosas usinas destinadas 
ao despolpamento, secagem, benefício e rebeneficio do café, nos Estados do Rio, de Minas e de São Paulo.

A fisionomia da Federação é completamente outra. Ela não mais seria reconhecida pelos patriarcas da República. A sua atividade se desdobra por todos os quadrantes do país. Ora é a Coordenação da Mobilização E'conómica, ora é o Conselho Federal do Comércio Exterior. Mil braços. se movimentam, alcançando tôdas as distâncias e dominando tôdas as dificuldades. Não é só a Banco do Brasil e nêle e Superintendência da Moedia e do Credito, mal disfarçando uma espécie de capitalismo de Estado, mas os Institutos de Previdência Social ou o Instituto do Açúcar, o do Mate, o de Pinho, o de Cacau, o de óleos, o do Sal, as Comissóes como a Comissão da Marinha Mercante ou da Comissão Executiva da Indústria Têxtil, os conselhos, como o Conselho Nacional da Economia, previsto pelo art. 205 da Constituição ou do Conselho Rodoviário Nacional. Em tôrno dessa nova superfácie, coberta pelo domínio federal, existe uma imensa legislação para alimentá-la, que vem desde a legislação militar até a ferroviária do Código das Minas, ao Código Florestal, da legislação sôbre o cooperativismo até o Código de Caça e Pesca.

Estabelecida, por fim, como inadiável, um programa de recuperação e aproveitamento dos valores económicos da Nação, como aconteceu nos Estados Unidos, deixamos ao encargo do govêrno federal as nossas áreas-problemas, as insidiosas dificuldades da Amazônia, do polígno da sêca, dos vales do nordeste, da bacia do São Francisco e o Rio Doce, do planalto central de Goiás. Concertada uma administração por planos, o govêrno federal não se limita ao aproveitamento nacional do vale do São Francisco e do rio Doce, à construção das rodovias nacionais, a penetração da previdência social em todos os Estados. Traça projetos: mais amplos como o do Plano Salte, tentativa governamental que tem como objetivo o desenvolvimento económico do país, a elevação dos níveis de vida, através da expansão. 
e coordenação dos serviços de fomento e das inversôes públicas.

A transformação radical do federalismo, que é uma consequência de sua própria índole e de um mundo em mudança, não pơde significar a sua prostração ou renúncia. Somos testemunhas de que a federação é uma esperança para a Europa e para a paz universal. E, nas repetidas campanhas nesse sentido lembram os seus defensores a Europa do Santo Império, de Otto I, de Carlos V, de Felipe II; ou senão, o Império Romano que, na evocação de Oliveira Martins, foi a mais expressiva forma de federação.

No desespêro das guerras mundiais em que vivemos eno tormento das revoluções incontáveis que nos deprimem, somos levados a ver, entretanto, nos braços armados da. centralização contemporânea, os gestos arrogantes da tirania e da prepotência. Porque há um perigo à vista, apesar de tôdas as sombras que nos envolvem. Há o p.erigo da federação sem fundamentos federativos do que falava CARLS Schmitr, da teratologia federativa, com o quadro de autonomias por fora e de centralização administrativa por dentro, aquêle mesmo federalismo nominal, a que se referia, com tanta antecipação, Alberto Tôrres.

$O$ instinto de conservação, que anima a nossa fé e a nossa crença, leva-nos, juristas, sociológos, políticos e homens do povo, a uma revisão de dados do federalismo para que, no novo equilíbrio social, se defenda uma vida digna de ser vivida.

Hoje, numa civilização em conflitos, somos obrigados: a escolher a um estilo de relações sociais e a procurar, com o novo material que o progresso das ofereceu, a seguranças jurídica indispensável.

Para que essa segurança não seja, no regime federativo. uma simples imagem, é necessário cue se considerem as novas fronteiras do direito, a existência de uma declaração internacional dos direitos do homem e o primado das rel:cões internacionais; que se compreenda que a "auto- 
determinação" e auto-suficiência" decorrem de valores inteiramente novos.

A federação, por isso, não pode ser apenas formal e política; não pode manter a sua vitalidade pelas velhas fontes individualistas, para se configurar como uma organização de uma magistratura impassível dada à União para presidir as atividades constitucionais dos Estadosmembros.

Vemo-la como um equilíbrio entre a união e a descentralização, entre o político e o social. E, nesse papel, a Federação se organiza, ao mesmo tempo em nome do reconhecimento das diferenças especúficas das comunidades locais, através da descentralização, e pela consagração de uma união especiffica, decorrente de uma mesma visão dos problemas de base, da mesma compreensão da socie.dade e do homem, da solidariedade e da justiça.

A propósito o plano Marshall, que estaria ameaçando a liberdade dos povos, disse o comentarista de uma revista francesa: "Êle deve ser aceito, uma vez que temos condições para reabastecer, com êle, as nossas liberdades"

E' só assim que podemos aceitar as transformações do federalismo e só assim, em seu novo aspecto, é que poderá ser traduzido em linguagem juridica.

Para que não se corrompa, entretanto, numa federação despojada e em ruínas; para que a descentralização não se converta em divisionismo político; para que a União não se implante como onipotência - temos que olhar frontalmente as 'verdades atuais, por mais incômodas que sejam e voltar nossas esperanças para a missão, por mais trabalhosa que se reconheça, dos estudiosos do direito público nacional, na preservação de nossa vida como organização e como liberdade. 